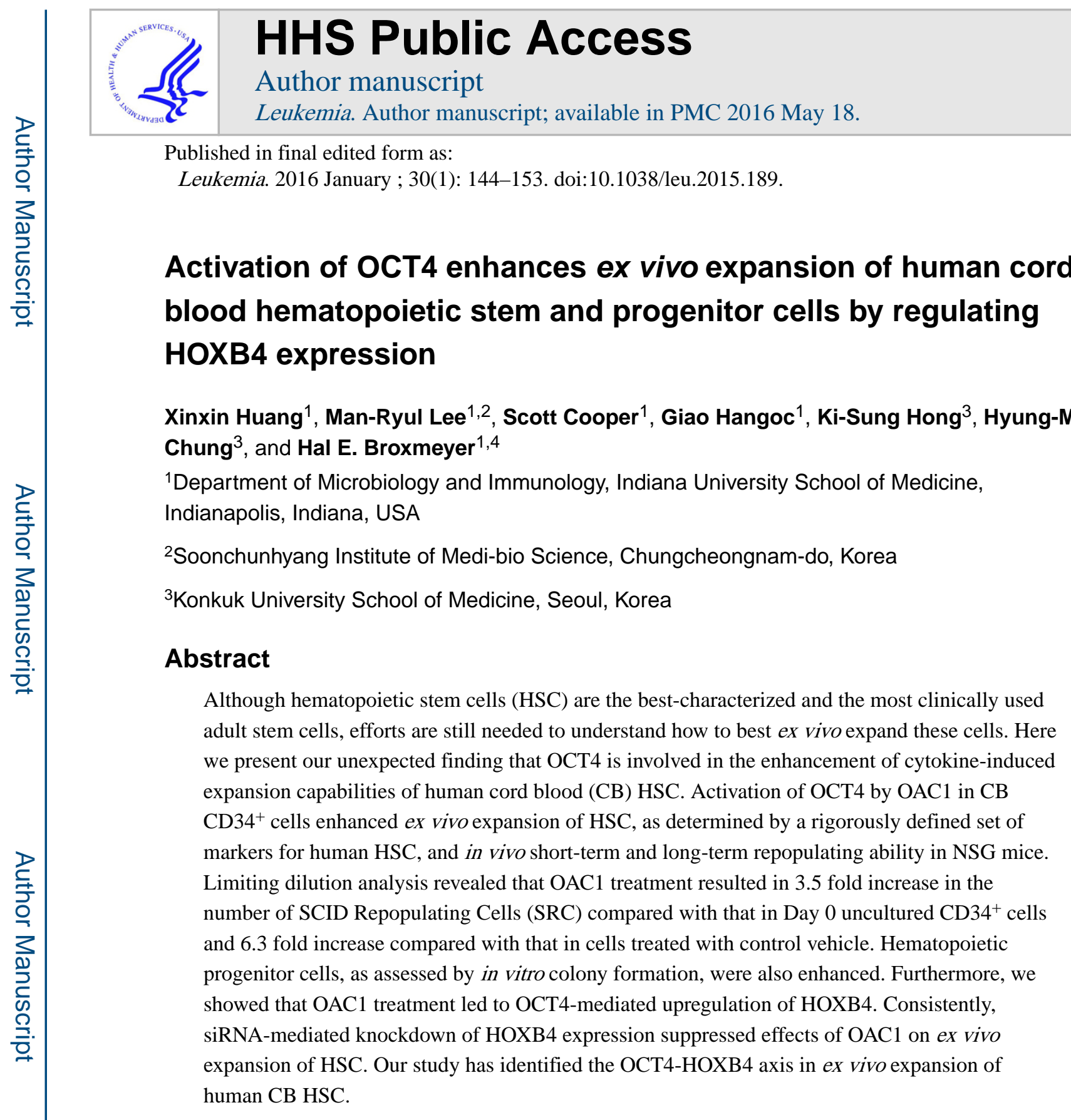

Published in final edited form as:

Leukemia. 2016 January ; 30(1): 144-153. doi:10.1038/leu.2015.189.

\title{
Activation of OCT4 enhances ex vivo expansion of human cord blood hematopoietic stem and progenitor cells by regulating HOXB4 expression
}

\author{
Xinxin Huang ${ }^{1}$, Man-Ryul Lee ${ }^{1,2}$, Scott Cooper ${ }^{1}$, Giao Hangoc ${ }^{1}$, Ki-Sung Hong $^{3}$, Hyung-Min

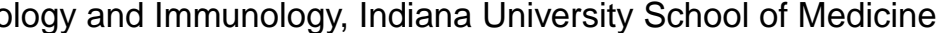 \\ ${ }^{2}$ Soonchunhyang Institute of Medi-bio Science, Chungcheongnam-do, Korea \\ Konkuk University School of Medicine, Seoul, Korea
}

\begin{abstract}
Although hematopoietic stem cells (HSC) are the best-characterized and the most clinically used adult stem cells, efforts are still needed to understand how to best ex vivo expand these cells. Here we present our unexpected finding that OCT4 is involved in the enhancement of cytokine-induced expansion capabilities of human cord blood (CB) HSC. Activation of OCT4 by OAC1 in CB CD $34^{+}$cells enhanced ex vivo expansion of HSC, as determined by a rigorously defined set of markers for human HSC, and in vivo short-term and long-term repopulating ability in NSG mice. Limiting dilution analysis revealed that $\mathrm{OAC} 1$ treatment resulted in 3.5 fold increase in the number of SCID Repopulating Cells (SRC) compared with that in Day 0 uncultured CD $34^{+}$cells progenitor cells, as assessed by in vitro colony formation, were also enhanced. Furthermore, we showed that OAC1 treatment led to OCT4-mediated upregulation of HOXB4. Consistently, siRNA-mediated knockdown of HOXB4 expression suppressed effects of OAC1 on ex vivo human CB HSC.
\end{abstract}

\footnotetext{
Users may view, print, copy, and download text and data-mine the content in such documents, for the purposes of academic research, subject always to the full Conditions of use:http://www.nature.com/authors/editorial_policies/license.html\#terms

${ }^{4}$ Correspondence to: Hal E. Broxmeyer, Ph.D., Department of Microbiology and Immunology, Indiana University School of Medicine, 950 West Walnut Street, R2-302, Indianapolis, IN 46202-5181 USA, Phone: 317-274-7510, Fax: 317-274-7592, ; Email: hbroxmey@iupui.edu

Conflict of interest

Hal E. Broxmeyer is a member of the Medical Scientific Advisory Board of CordUse, a cord blood banking company based in Orlando, Florida. The remaining authors declare no conflict of interest.

Author contributions

$\mathrm{XH}$ and HEB directed the research, designed and performed experiments, interpreted data and wrote the manuscript. SC and GH performed experiments, and interpreted data. ML, $\mathrm{KH}$ and $\mathrm{HC}$ performed the teratoma study and interpreted data.
} 


\section{Introduction}

Hematopoietic stem cells (HSC) are responsible for maintaining and replenishing all blood cell lineages during a lifetime. Allogeneic hematopoietic cell transplantation (HCT) is well established as a clinical means to treat patients with hematologic disorders and cancer. Human cord blood is an alternative source of HSC for transplantation ${ }^{1-3}$; the advantages of using CB as a hematopoietic source for HCT are: easy accessibility of banked HLA-typed $\mathrm{CB}$ and, decreased graft-versus-host disease. However, numbers of nucleated cells retrieved, as well as limited numbers of HSC/progenitor (HPC) cells present, during collection may be problematic for treatment of adult patients with single CB HCT. One means to address the problem of limiting numbers of HSC/HPC is to ex vivo expand these cells for potential clinical use. While progress has been made in this endeavor ${ }^{1}{ }^{4,}$, , there is still a clinically relevant need for additional means to ex vivo expand human HSC and HPC.

The POU domain family transcriptional factor Octamer binding protein 4 (OCT4) is well defined as a master regulator for maintenance of totipotency and pluripotency ${ }^{6}$. In embryonic stem cells, OCT4, SOX2 and NANOG form a regulatory circuitry to orchestrate self-renewal and suppress differentiation ${ }^{7}$. In vivo expression of OCT4 and three other transcriptional factors enable reprogramming of somatic cells to induced pluripotent stem cells ${ }^{8}$. Surprisingly, ectopic expression of OCT4, together with cytokine treatment, allowed generation of human hematopoietic progenitor cells from fibroblasts, suggesting an unexpected role of OCT4 during hematopoietic fate transition ${ }^{9}$. Recently, a small molecule library screen identified Oct4-activating compound $1(\mathrm{OAC} 1)$ as a reagent to increase the expression of the endogenous Oct 4 . OAC 1 facilitated the reprogramming of cells by enhancing efficiency and shortening the reprogramming time ${ }^{10}$. Additionally, Oct4 gene expression has been reported in a variety of adult stem cells, including breast stem cells, pancreatic stem cells, liver stem cells, mesenchymal stem cells and HSC suggesting that OCT4 might also function in somatic stem cells ${ }^{11 \_13}$. However, the functions of OCT4 in somatic stem cells, especially in HSC are largely unknown.

In this study we hypothesized that OCT4 is involved in HSC function and expansion, and thus we evaluated the effects of $\mathrm{OAC} 1$ on ex vivo culture of $\mathrm{CB} \mathrm{CD} 34^{+}$cells in the presence of a cocktail of cytokines known to enhance ex vivo expansion of human HSCs. We found that $\mathrm{CB} \mathrm{CD} 34^{+}$cells treated with $\mathrm{OAC} 1$ showed a significant increase above that of this cytokine cocktail in the numbers of rigorously defined HSC by phenotype and in vivo repopulating capacity in NSG mice, and in numbers of multipotential, erythroid and granulocyte macrophage progenitors as determined by colony assays. We identified HOXB4 as a crucial downstream target of OCT4 and showed that OCT4-HOXB4 axis was essential for OAC1-mediated HSC expansion. We did not detect leukemic transformation of engrafted cells within the time frame of our experimental observations nor did the cells form teratomas in mice. Our data show, for the first time, a functional link between OCT4 expression and HSC function, and suggest the potential clinical application of using OAC1, or next generation OCT4 activators, to ex vivo expand human HSC. 


\section{Materials and Methods}

Mice

All experimental procedures with mice were approved by The Institutional Animal Care and Use Committee of the Indiana University School of Medicine. NSG (NOD.Cg-

$\mathrm{Prkdc}^{\mathrm{scid}} \mathrm{Il} 2 \mathrm{rg}^{\mathrm{tm}} 1 \mathrm{Wjl} / \mathrm{Sz}$; 8-10 weeks old) mice were obtained from an on-site core breeding colony supported at our NIDDK Center of Excellence in Molecular Hematology and the NCI-designated Indiana University Simon Cancer Center.

\section{In vitro cell cultures}

Normal human cord blood was provided by CordUse, a cord blood banking company. Mononuclear cells were isolated by density gradient centrifugation over Ficoll-Paque Plus (GE Healthcare). CD34+ cells were obtained by immunomagnetic selection (Miltenyi Biotec, Auburn, CA, USA) over two sequential columns. This yields $90-98 \%$ purity of CD34+ cells. CD34+ cells were then cultured in RPMI-1640 medium containing 10\% FBS, $100 \mathrm{ng} / \mathrm{mL}$ stem cell factor (SCF), thrombopoietin (TPO), Fms-like tyrosine kinase 3 ligand (Flt3L), in the presence of 500nM OAC1 (Xcessbio, San Diego, CA, USA) or with a vehicle control (DMSO). For lentiviral vector transduction, $\mathrm{CB}$ CD34 ${ }^{+}$cells were transduced with lentiviral vector pCSC-GW and pCSC-OCT4 (OCT4 cDNA was cloned into AgeI site in pCSC-GW plasmid) as previous described ${ }^{14}$, transduced $\mathrm{CD} 34^{+}$cells were cultured for 4 days before flow analysis.

\section{Flow cytometry and antibodies}

Cells were stained at $4^{\circ} \mathrm{C}$ for 30 minutes with the following antibodies: Lineage cocktail (Lin)-FITC, CD34-APC (581), CD38-PE (HIT2), CD45RA-PECF594 (HI100), CD90PEcy7 (5E10), and CD49f-PerCPcy5.5 (GoH3) for phenotypic analysis of HSC and HPC; CD3-FITC (UCHT1), CD19-PE (HIB19), CD33-FITC (WM53), CD45-APC (HI30) were used for in vivo transplantation. All the above antibodies were purchased from BD Bioscience. For intracellular staining, $\mathrm{CD} 34^{+}$cells were fixed, permeabilized and stained with OCT4 (C-10, Santa Cruz), SOX2 (57CT23.3.4, Abcam), NANOG (H-155, Santa Cruz) or HOXB4 (EP1919Y, Abcam) primary antibodies. Cells were washed and then stained with FITC-conjugated secondary antibody for 30 minutes on ice, light protected. Flow analysis was performed with a BD Bioscience LSR II and FlowJo software. The negative portion was determined by using relevant isotype antibody controls.

\section{In vitro colony-forming unit (CFU) assay}

$\mathrm{CB} \mathrm{CD} 34^{+}$cells were seeded in triplicate in $1.0 \mathrm{~mL}$ methylcellulose culture medium supplement with 30\% FBS, $2 \mathrm{mM} \mathrm{L-glutamine,} 0.1 \mathrm{mM}$ 2-mercaptoethanol, and recombinant human cytokines: $1 \mathrm{U} / \mathrm{mL}$ erythropoietin, $50 \mathrm{ng} / \mathrm{mL} \mathrm{SCF}, 10 \mathrm{ng} / \mathrm{mL}$ interleukin-3 (IL-3), and $10 \mathrm{ng} / \mathrm{mL}$ granulocyte-macrophage colony-stimulating factor (GM$\mathrm{CSF}$ ). The number of colonies was scored at Day 14 with an inverted microscope. All cell cultures were incubated in a $5 \% \mathrm{O}_{2} / 5 \% \mathrm{CO}_{2}$ humidified chamber. 


\section{In vivo transplantation}

Transplantation of human cells into NSG mice was done as described previously ${ }^{14},{ }^{15}$. Briefly, 8-10 week old NSG mice were sublethally irradiated (350cGy; ${ }^{137} \mathrm{Cs}$ source, single dose) and transplanted with progeny of $50000 \mathrm{OAC} 1$ or vehicle control treated $\mathrm{CB}$ CD34 ${ }^{+}$ cells within $24 \mathrm{~h}$ after irradiation. Peripheral bloods were collected at various time points by tail-vein bleeding. The blood samples were treated with RBC lysis buffer and then washed in PBS $+1 \%$ BSA buffer before staining. Peripheral blood collected from untransplanted NSG mouse was used as a negative control. Mice were sacrificed 16 weeks after transplantation. For long-term engraftment assay, $2 \times 10^{6} \mathrm{BM}$ cells from the primary recipient mice were infused into secondary recipient mice. These mice were also sacrificed 16 weeks after transplantation. BM cells were stained and analyzed by flow cytometry as described above.

\section{Limiting dilution analysis}

The frequency of human SRCs in uncultured CD34 ${ }^{+}$cells and the progeny of an equivalent number of $\mathrm{CD}_{3} 4^{+}$cells that were ex vivo expanded in the presence of vehicle control or $\mathrm{OAC} 1$ were analyzed by limiting dilution assay as reported by others ${ }^{4}$. Increasing doses of uncultured $\mathrm{CD}_{3} 4^{+}$cells $(500,2500,5000)$ or the progeny of an equivalent number of $\mathrm{CD} 34^{+}$ cells were infused into NSG mice. These mice were sacrificed 12 weeks after transplantation. The HSC frequency was calculated using L-Calc software (StemCell Technologies Inc.) and plotted using ELDA software (bioinf.wehi.edu.au/software/elda/).

\section{siRNA-mediated knockdown analysis}

CB CD34+ cells were transfected with 40nM OCT4 (sc-36123), HOXB4 (sc-38692) or scrambled siRNA (sc-37007) according to the manufacturer's instructions (Santa cruz). OCT4 and HOXB4 protein expression levels were assessed following siRNA knockdown. Cells treated with siRNA were stained after 4 days of culture in the presence of vehicle control or OAC1, and analyzed by flow cytometry for HSC fraction.

\section{In vivo teratoma formation assay}

$1 \times 10^{6} \mathrm{CD} 34^{+}$cells from vehicle control cultures or cultures containing $\mathrm{OAC} 1$ or $1 \times 10^{6}$ human H9 ES cells were subcutaneously injected into 6-week-old, Athymic nude mice ${ }^{16}$. The resulting teratomas were removed 6 weeks later. Samples from the teratomas were paraffin-embedded and serially sectioned using microtome (Leica Microsystems, Wetzlar, Germany). To analyze the three germ-layer lineage cells derived from injected H9 ES cells in the teratomas, sectioned slides were stained with hematoxylin and eosin (HE stain). Images were analyzed using an inverted microscope system (Nikon).

\section{Statistical analysis}

Results are expressed as mean values \pm standard deviation. $P$ value less than 0.05 (two tailed student $t$ test) was considered as statistically significant. 


\section{Results}

\section{OAC1 treatment results in increased numbers of phenotypic HSC and functional HPC}

To test whether activation of OCT4 is involved in expansion of HSC, CD34 ${ }^{+}$cells from human cord blood were cultured for 4 days in medium containing $100 \mathrm{ng} / \mathrm{mL}$ of SCF, TPO and Flt3L with and without the OCT4 activator compound $\mathrm{OAC} 1{ }^{10}$. A concentration of 500nM OAC1, was the most effective for ex vivo HSC expansion (Supplementary Figure 1A). The protein level of OCT4 expression greatly increased after culture of CB CD34+ cells with OAC1 (Figure 1a). Since OCT4, SOX2 and NANOG form an autoregulatory feedback loop, we also observed upregulation of SOX2 and NANOG in OAC1-treated cells (Supplementary Figures 2A and 2B). To assess whether OAC1 affects the epigenetic states in $\mathrm{CD} 34^{+}$cells, we examined the levels of Histone 3 lysine 4 trimethylation $(\mathrm{H} 3 \mathrm{~K} 4 \mathrm{me} 3)$ and Histone 3 lysine 9 trimethylation (H3K9me3) in OAC1-treated cells. H3K4me3 is known to be associated with transcriptional active state, while $\mathrm{H} 3 \mathrm{~K} 9 \mathrm{me} 3$ has been well characterized as a mark of transcriptional inactive state ${ }^{17}$. The levels of H3K4me3 and H3K9me3 did not show significant difference in OAC1-treated cells (Supplementary Figures 2C and 2D), suggesting that $\mathrm{OAC} 1$ did not affect the epigenetic marks of these cells.

We firstly observed that numbers of $\mathrm{CD} 34^{+} \mathrm{CD} 38^{-}$cells significantly increased in the OAC1 treated group after culture compared with the vehicle treated group (Figures $1 \mathrm{~b}$ and $\mathrm{c}$ ). We then carefully examined the effect of $\mathrm{OAC} 1$ in a more rigorously defined most primitive $\left(\mathrm{Lin}^{-} \mathrm{CD} 34^{+} \mathrm{CD} 38^{-} \mathrm{CD} 45 \mathrm{RA}^{-} \mathrm{CD} 90^{+} \mathrm{CD} 49 \mathrm{f}^{+}\right)$HSC population ${ }^{18}$. We found that there was a 7.6 fold increase in these cells in the OAC1 treated group compared with uncultured Day0 group, and a 2.8 fold increase compared with vehicle treated group (Figures $1 \mathrm{~b}$ and d). To further confirm the role of OCT4 during ex vivo HSC culture, we performed OCT4 overexpression in $\mathrm{CB} \mathrm{CD} 34^{+}$cells using lentiviral vectors and found that overexpression of OCT4 also resulted in significant increase in the number of phenotypic HSC compared to control vectors (Figure 1e). There was also a significant increase in phenotypic HSC for 7 days in the presence of OAC1 (Supplementary Figure 3A). Also, the effect of OAC1 was reproducible when $\mathrm{CB}$ CD34 ${ }^{+}$cells were cultured in serum-free medium Stemline II (Supplementary Figure 3B). We also noticed that the number of phenotypically-defined endothelial progenitor cells (EPC, $\mathrm{CD} 133^{+} \mathrm{CD} 309^{+} \mathrm{CD} 34^{+}$) significantly increased in the OAC1 treated group, while the number of mesenchymal stromal cells (MSC, $\mathrm{CD} 45^{-} \mathrm{CD} 73^{+} \mathrm{CD} 105^{+} \mathrm{CD} 90^{+}$) did not show significant differences in the OAC1 treated group (Supplementary Figure $3 \mathrm{C}$ and $3 \mathrm{D}$ ). Therefore, our results suggest that $\mathrm{OAC} 1$ facilitates cytokine stimulated ex vivo CB HSC expansion.

To assess whether OAC1 also enhanced cytokine stimulated ex vivo expansion of HPC, CB $\mathrm{CD}_{4} 4^{+}$cells treated with the cytokine combination with either $\mathrm{OAC} 1$ or vehicle control were seeded in semisolid methylcellulose culture medium and cultured for 14 days in the presence of a maximally stimulatory combination of cytokines (Erythropoietin, SCF, IL-3 and GMCSF). OAC1 significantly increased numbers of granulocyte/macrophage (CFU-GM), erythroid (BFU-E), and granulocyte, erythroid, macrophage, megakaryocyte (CFU-GEMM) progenitors after 4 days ex vivo culture (Figure 2a), demonstrating that OAC1 also enhances cytokine-stimulated ex vivo expansion of functionally recognizable HPC. To further confirm 
that $\mathrm{OAC} 1$ enhances ex vivo expansion of HPC, suboptimal cytokine doses were either employed during ex vivo expansion (SCF, TPO and Flt3L), or during the CFU assay (Erythropoietin, SCF, IL-3 and GM-CSF). Significant increases in CFU numbers in OAC1 treated group were observed in both situations (Figure $2 b$ and $2 c$ ), suggesting that OAC1 enhances ex vivo expansion of HPC with both full and suboptimal cytokine doses in the expansion and colony forming phases.

\section{Culture of $\mathrm{CB} C D 34^{+}$with OAC1 enhances short and long-term engrafting HSC}

The human cell immune-deficient mouse engraftment assay currently serves as the best model for determining functionality of human $\mathrm{HSC}^{19}$. To evaluate the functionality of OAC1-treated $\mathrm{CD} 34^{+}$cells, sublethally irradiated NSG mice were transplanted with the progeny of $50000 \mathrm{CB} \mathrm{CD} 34^{+}$cells that had been cultured for 4 days with SCF, TPO and Flt3L and with $\mathrm{OAC} 1$ or vehicle control. We observed significantly increased engraftment of $\mathrm{OAC} 1$ treated $\mathrm{CB}$ cells in primary recipients, compared to the vehicle control group (Figures $3 \mathrm{a}$ and $3 \mathrm{~b}$ ), with across the board increase for human B cells, $\mathrm{T}$ cells and myeloid cells in the bone marrow (BM) of primary recipients (Figure 3c). To determine whether OAC1expanded cells had self-renewal capability, we transplanted BM cells from primary NSG mice 16 weeks after transplantation into secondary sublethally irradiated NSG mice. We found that the OAC1 expanded group also resulted in greater engraftment of human CD45 cells in secondary mouse recipients (Figure 3d), suggesting that we had increased the longterm engrafting capacity of self-renewing HSC after OAC1 treatment.

To assess the degree of HSC expansion by OAC1 treatment, we did a limiting dilution assay to compare the frequency of SRCs in Day 0 uncultured CD34 ${ }^{+}$cells, in the progeny of an equivalent number of cells in the presence of vehicle control, or OAC1 after 4 days ex vivo culture (Table 1). Poisson distribution analysis revealed an SRC frequency of 1/3723 in Day 0 uncultured $\mathrm{CD}^{+} 4^{+}$cells, 1/6682 in vehicle control cultures and 1/1060 in cultures treated with OAC1 (Figure 4a). We calculated the presence of 269 SRCs in $1 \times 10^{6}$ Day 0 uncultured CD34 ${ }^{+}$cells, 150 SRCs and 943 SRCs in $1 \times 10^{6}$ cells from vehicle control and OAC1-treated cultures respectively (Table 2). So OAC1 treatment resulted in 3.5 fold increase in the number of SRCs compared with that in Day 0 uncultured CD34 ${ }^{+}$cells and 6.3 fold increase compared with that in cells treated with control vehicle (Figure 4b). Our data demonstrate that $\mathrm{CB}$ CD $34^{+}$cells cultured with OAC1 results in a significant expansion of SRC numbers.

\section{HOXB4 is essential for OAC1-mediated expansion of cord blood HSC}

HOXB4 is a homeobox transcriptional factor that appears to be an essential regulator of HSC self-renewal; overexpression of HOXB4 resulted in high-level ex vivo HSC expansion $^{20},{ }^{21}$. Also, it has been reported that OCT4 could bind to the promoter region of HOXB 4 at the site of $2952 \mathrm{bp}$ from transcription start point ${ }^{7}$. So, we hypothesized that activation of OCT4 might work through upregulation of HOXB4 expression to ex vivo expand HSC. The expression level of HOXB4 in human CB CD34+ cells was assessed by flow cytometry after 4 days treatment with $\mathrm{OAC} 1$ or vehicle control. We observed that the expression of HOXB4 was significantly increased after culture of $\mathrm{CB} \mathrm{CD} 34^{+}$cells with $\mathrm{OAC} 1$ compared to vehicle control (Figure 5a). To further confirm a functional link between upregulation of HOXB4 in OAC1-treated cells and the expansion of primitive HSC, we 
transfected $\mathrm{CD} 34^{+}$cells with $H O X B 4$ siRNA. siRNA-mediated $H O X B 4$ knockdown led to a significant reduction in the absolute number of $\mathrm{Lin}^{-} \mathrm{CD} 34^{+} \mathrm{CD} 38^{-} \mathrm{CD} 45 \mathrm{RA}^{-} \mathrm{CD} 90^{+} \mathrm{CD}^{-} \mathrm{f}^{+}$ cells in OAC1-treated cells (Figure 5b), suggesting HOXB4 is essential for the generation of primitive HSC in OAC1-treated cells. Next, we asked whether OCT4 is required for the upregulation of HOXB4 in OAC1-treated cells by using OCT4 siRNA. Similar with HOXB4 siRNA, knockdown of OCT4 led to a significant reduction in phenotypic HSC (Figure 5b). Furthermore, we found that siRNA mediated inhibition of OCT4 also resulted in marked reduction of HOXB4 expression in OAC1-treated cells (Figure 5c), while knockdown of HOXB4 did not affect the expression of OCT4 in OAC1-treated cells (Figure 5d), suggesting HOXB4 is downstream of OCT4 during ex vivo expansion of CB HSC.

Additionally, we tested whether knockdown of $H O X B 4$ affects OAC1-mediated expansion of HPC. CB CD34+ cells were transfected with $H O X B 4$ siRNA or OCT4 siRNA and then cultured with the cytokine combination with either OAC1 or vehicle control for 4 days. The treated cells were seeded in semisolid methylcellulose culture medium and cultured for 14 days. We observed that knockdown of HOXB4 or OCT4 also blocked OAC1-mediated increased numbers of CFU-GM and CFU-GEMM colonies (Supplementary Figure 4A). To further demonstrate that OCT4 binds to the HOXB4 promoter region in HSC, we carried out a ChIP analysis using anti-OCT4 antibody. Consistently, we found that immunoprecipitation with OCT4 antibody showed marked enrichment for the $-3000 \mathrm{bp}$ of the HOXB4 promoter region (Supplementary Figure 4B). Taken together, our data indicate that OAC1 treatment leads to OCT4-mediated upregulation of HOXB4, which is essential for the generation of

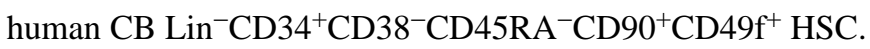

\section{OAC1 treated CD $34^{+}$cells did not form teratoma in vivo}

To exclude the possibility that the expanded cells contained leukemogenic potential, we followed the survival ratio of NSG mice transplanted with vehicle control or OAC1 treated CD $34^{+}$cells. Within the time frame of our experiments (up to 16 weeks post-transplant), there was no significant difference between vehicle control group and OAC1 treated group (Supplementary Figure 5, p>0.05), nor did we detect any evidence of the generation of leukemic cells, suggesting that $\mathrm{OAC} 1$ treatment did not cause malignant transformation of $\mathrm{CD} 34^{+}$cells during our observation periods.

Since OCT4 expression has been associated with induction of pluripotency that could potentially lead to the formation of teratomas, $\mathrm{CD} 34^{+}$cells from vehicle control cultures, OAC1 treatment cultures or human H9 ES cells were each injected subcutaneously into nude mice and were examined after 6 weeks. Teratomas, containing tissue from all three germ layers, formed from the H9 ES cells (Supplementary Figure 6) that were not observed in animals injected with $\mathrm{CD} 34^{+}$cells from vehicle control cultures or OAC1 treatment cultures.

\section{Discussion}

Understanding the regulation of HSC by intrinsic and extrinsic factors is important for improving HCT. Although many extrinsic factors have been identified as regulators of HSC, such as cytokines $^{22}$, Notch ligands ${ }^{23}$, Wnt ligands ${ }^{24}$, and Angiopoietins ${ }^{25}$, to the best of our knowledge, HOXB4 is the only intrinsic factor that shows positive effects on ex vivo HSC 
expansion. Here we demonstrate that OCT4 is another intrinsic factor that plays an important role in HSC expansion. By utilization of OAC1, we observed significant increase in the number of phenotypic HSC, HPC, and short-term and long-term HSC in vivo repopulating capability.

We used a simple HSC culture medium containing SCF, TPO and Flt3L, with or without serum, and in this system we observed OCT4-mediated HSC expansion in 4 days. The quality of the OAC1-expanded HSC did not appear to be impaired, as they showed multilineage repopulating capability. Besides, all NSG mice transplanted with OAC1expanded cells remained healthy and without any obvious disorders. Our study also followed engraftment in secondary transplanted animals for 4 months after 4-months engraftment in primary mice, suggesting that the enhancement was for long-term repopulating, selfrenewing HSC. While we did not detect any leukemic transformation of cells engrafted with eX-vivo cultured $\mathrm{CD} 34^{+} \mathrm{CB}$ cells for up to 16 weeks, and did not detect any teratoma formation by these cultured cells when injected into mice, we can not completely rule out the possibility that the ex vivo expanded cells contained leukemogenic potential. This is always the concern for all the ex vivo modified cells regardless of how they are expanded. Future studies on non human primates and humans may be needed before full clinical safety is known.

How physiological HSC self-renewal is regulated remains incompletely understood. Our data showed, for the first time, that overexpression of OCT4 enhanced ex vivo HSC expansion and suggest that OCT4 plays an essential role in HSC self-renewal. Direct generation of progenitors of hematopoietic fate from human dermal fibroblasts by ectopic expression of OCT4 has recently been reported ${ }^{9}$, and this finding reinforces our current study, that indicates OCT4 as a component in HSC biology. OCT4 expression in somatic stem cells has been described ${ }^{11 \_13}$, however, the links to functional activities are largely missing. Previously, it was reported that Oct 4 gene ablation in mice did not show significant difference in various tissues, including intestine, bone marrow and brain ${ }^{26}$. However, these results could be explained by the functional redundancy within the Oct family and Pou domain family and could not rule out the possibility that overexpression of Oct4 would have impact in these tissues. Recent reports also showed that overexpression of OCT4 increased the proliferative capacity and functionality of mesenchymal stem cells ${ }^{27}, 28$. Our data indicate activation of OCT4 by OAC1 or lentiviral vector is sufficient to enhance HSC expansion while preserving the functionality. This information raises a number of important possibilities regarding the function of OCT4 in other types of somatic stem cells.

The human homeodomain containing transcription factor HOXB4 was the first gene shown to dramatically expand murine HSC when ectopically expressed ${ }^{20}$. Ectopic expression of HOXB4 also enhanced the generation of definitive HSC from murine ES cells ${ }^{29}$. TATHOXB4 and degradation-resistant HOXB4 variant also markedly enhanced ex vivo expansion of human $\mathrm{HSC}^{21},{ }^{30}$. These studies demonstrated that the function of HOXB4 is important for HSC. We found that the expression of HOXB4 protein was largely increased in OAC1-treated $\mathrm{CD} 34^{+}$cells, and knockdown of HOXB4 blocked the ex vivo expansion of CB HSC by OAC1, suggesting HOXB4 as a key component in mediating OCT4 function in ex vivo HSC expansion. 
As reported, detection of OCT4 expression by RT-PCR could be misled by pseudogene transcripts $^{31}$, so we examined the protein expression level of OCT4 in CB CD34 ${ }^{+}$cells and showed that significant elevation of OCT4 protein expression was observed in $\mathrm{CB}$ CD34 ${ }^{+}$ cells treated with OAC1. Recently, it was reported that valproic acid treatment also led to upregulation of OCT4, SOX2 and NANOG, which is essential for the valproic acidmediated expansion of cord blood stem cells ${ }^{32}$. In our study, we emphasized that the function of OCT4 was crucial during ex vivo CB HSC expansion and demonstrated that HOXB4 was a important downstream target in mediating ex vivo HSC expansion by OCT4.

In summary, overexpression of OCT4 by OAC 1 regulates ex vivo HSC expansion by regulating HOXB4 expression, the data presented here suggest the importance of OCT4 in HSC function. It would be interesting to explore the potential of OAC1 treatment for translation to clinical HSC transplantation and to search for better structural analogs of OAC1 that will be more effective in enhancing ex vivo HSC expansion. The approach used in our report may have the potential to generate sufficient numbers of in vivo repopulating HSC to facilitate allogeneic CB HCT.

\section{Supplementary Material}

Refer to Web version on PubMed Central for supplementary material.

\section{Acknowledgments}

We sincerely thank other lab members in Dr. Broxmeyer's laboratory for helpful discussion. This work was supported by Public Health Service Grants from the NIH to HEB: R01 HL056416, R01 HL67384, R01 HL112669, and NIH P01 DK090948. The teratoma study was supported by grant HI14C3365 from the Ministry for Health\&Welfare by the Korean government.

\section{References}

1. Ballen KK, Gluckman E, Broxmeyer HE. Umbilical cord blood transplantation: the first 25 years and beyond. Blood. 2013 Jul 25; 122(4):491-498. [PubMed: 23673863]

2. Broxmeyer HE, Douglas GW, Hangoc G, Cooper S, Bard J, English D, et al. Human umbilical cord blood as a potential source of transplantable hematopoietic stem/progenitor cells. Proceedings of the National Academy of Sciences of the United States of America. 1989 May; 86(10):3828-3832. [PubMed: 2566997]

3. Gluckman E, Broxmeyer HA, Auerbach AD, Friedman HS, Douglas GW, Devergie A, et al. Hematopoietic reconstitution in a patient with Fanconi's anemia by means of umbilical-cord blood from an HLA-identical sibling. The New England journal of medicine. 1989 Oct 26; 321(17):11741178. [PubMed: 2571931]

4. Boitano AE, Wang J, Romeo R, Bouchez LC, Parker AE, Sutton SE, et al. Aryl hydrocarbon receptor antagonists promote the expansion of human hematopoietic stem cells. Science (New York, NY). 2010 Sep 10; 329(5997):1345-1348.

5. Fares I, Chagraoui J, Gareau Y, Gingras S, Ruel R, Mayotte N, et al. Cord blood expansion. Pyrimidoindole derivatives are agonists of human hematopoietic stem cell self-renewal. Science (New York, NY. 2014 Sep 19; 345(6203):1509-1512.

6. Nichols J, Zevnik B, Anastassiadis K, Niwa H, Klewe-Nebenius D, Chambers I, et al. Formation of pluripotent stem cells in the mammalian embryo depends on the POU transcription factor Oct4. Cell. 1998 Oct 30; 95(3):379-391. [PubMed: 9814708] 
7. Boyer LA, Lee TI, Cole MF, Johnstone SE, Levine SS, Zucker JP, et al. Core transcriptional regulatory circuitry in human embryonic stem cells. Cell. 2005 Sep 23; 122(6):947-956. [PubMed: 16153702]

8. Takahashi K, Yamanaka S. Induction of pluripotent stem cells from mouse embryonic and adult fibroblast cultures by defined factors. Cell. 2006 Aug 25; 126(4):663-676. [PubMed: 16904174]

9. Szabo E, Rampalli S, Risueno RM, Schnerch A, Mitchell R, Fiebig-Comyn A, et al. Direct conversion of human fibroblasts to multilineage blood progenitors. Nature. 2010 Nov 25; 468(7323):521-526. [PubMed: 21057492]

10. Li W, Tian E, Chen ZX, Sun G, Ye P, Yang S, et al. Identification of Oct4-activating compounds that enhance reprogramming efficiency. Proceedings of the National Academy of Sciences of the United States of America. 2012 Dec 18; 109(51):20853-20858. [PubMed: 23213213]

11. Tai MH, Chang CC, Kiupel M, Webster JD, Olson LK, Trosko JE. Oct4 expression in adult human stem cells: evidence in support of the stem cell theory of carcinogenesis. Carcinogenesis. 2005 Feb; 26(2):495-502. [PubMed: 15513931]

12. Goolsby J, Marty MC, Heletz D, Chiappelli J, Tashko G, Yarnell D, et al. Hematopoietic progenitors express neural genes. Proceedings of the National Academy of Sciences of the United States of America. 2003 Dec 9; 100(25):14926-14931. [PubMed: 14634211]

13. Tondreau T, Meuleman N, Delforge A, Dejeneffe M, Leroy R, Massy M, et al. Mesenchymal stem cells derived from CD133-positive cells in mobilized peripheral blood and cord blood: proliferation, Oct4 expression, and plasticity. Stem cells (Dayton, Ohio). 2005 Sep; 23(8):11051112.

14. Liu Y, Hangoc G, Campbell TB, Goodman M, Tao W, Pollok K, et al. Identification of parameters required for efficient lentiviral vector transduction and engraftment of human cord blood CD34(+) NOD/SCID-repopulating cells. Experimental hematology. 2008 Aug; 36( 8):947-956. [PubMed: 18640494]

15. Rohrabaugh SL, Campbell TB, Hangoc G, Broxmeyer HE. Ex vivo rapamycin treatment of human cord blood CD34+ cells enhances their engraftment of NSG mice. Blood cells, molecules \& diseases. 2011 Apr 15; 46(4):318-320.

16. Lee MR, Prasain N, Chae HD, Kim YJ, Mantel C, Yoder MC, et al. Epigenetic regulation of NANOG by miR-302 cluster-MBD2 completes induced pluripotent stem cell reprogramming. Stem cells (Dayton, Ohio). 2013 Apr; 31(4):666-681.

17. Mikkelsen TS, Ku M, Jaffe DB, Issac B, Lieberman E, Giannoukos G, et al. Genome-wide maps of chromatin state in pluripotent and lineage-committed cells. Nature. 2007 Aug 2; 448(7153):553560. [PubMed: 17603471]

18. Notta F, Doulatov S, Laurenti E, Poeppl A, Jurisica I, Dick JE. Isolation of single human hematopoietic stem cells capable of long-term multilineage engraftment. Science (New York, NY). 2011 Jul 8; 333(6039):218-221.

19. Broxmeyer HE, Lee MR, Hangoc G, Cooper S, Prasain N, Kim YJ, et al. Hematopoietic stem/ progenitor cells, generation of induced pluripotent stem cells, and isolation of endothelial progenitors from 21- to 23.5-year cryopreserved cord blood. Blood. 2011 May 5; 117(18):47734777. [PubMed: 21393480]

20. Antonchuk J, Sauvageau G, Humphries RK. HOXB4-induced expansion of adult hematopoietic stem cells ex vivo. Cell. 2002 Apr 5; 109(1):39-45. [PubMed: 11955445]

21. Lee J, Shieh JH, Zhang J, Liu L, Zhang Y, Eom JY, et al. Improved ex vivo expansion of adult hematopoietic stem cells by overcoming CUL4-mediated degradation of HOXB4. Blood. 2013 May 16; 121(20):4082-4089. [PubMed: 23520338]

22. Zon LI. Intrinsic and extrinsic control of haematopoietic stem-cell self-renewal. Nature. 2008 May 15; 453(7193):306-313. [PubMed: 18480811]

23. Dahlberg A, Delaney C, Bernstein ID. Ex vivo expansion of human hematopoietic stem and progenitor cells. Blood. 2011 Jun 9; 117(23):6083-6090. [PubMed: 21436068]

24. Povinelli BJ, Nemeth MJ. Wnt5a regulates hematopoietic stem cell proliferation and repopulation through the Ryk receptor. Stem cells (Dayton, Ohio). 2014 Jan; 32(1):105-115.

25. Zhang CC, Kaba M, Ge G, Xie K, Tong W, Hug C, et al. Angiopoietin-like proteins stimulate ex vivo expansion of hematopoietic stem cells. Nature medicine. 2006 Feb; 12( 2):240-245. 
26. Lengner CJ, Camargo FD, Hochedlinger K, Welstead GG, Zaidi S, Gokhale S, et al. Oct4 expression is not required for mouse somatic stem cell self-renewal. Cell stem cell. 2007 Oct 11; 1(4):403-415. [PubMed: 18159219]

27. Han SH, Jang G, Bae BK, Han SM, Koh YR, Ahn JO, et al. Effect of ectopic OCT4 expression on canine adipose tissue-derived mesenchymal stem cell proliferation. Cell biology international. 2014 Oct; 38(10):1163-1173. [PubMed: 24797505]

28. Han SM, Han SH, Coh YR, Jang G, Chan Ra J, Kang SK, et al. Enhanced proliferation and differentiation of Oct4- and Sox2-overexpressing human adipose tissue mesenchymal stem cells. Experimental \& molecular medicine. 2014; 46:e101. [PubMed: 24946789]

29. Kyba M, Perlingeiro RC, Daley GQ. HoxB4 confers definitive lymphoid-myeloid engraftment potential on embryonic stem cell and yolk sac hematopoietic progenitors. Cell. $2002 \mathrm{Apr} 5$; 109(1):29-37. [PubMed: 11955444]

30. Krosl J, Austin P, Beslu N, Kroon E, Humphries RK, Sauvageau G. In vitro expansion of hematopoietic stem cells by recombinant TAT-HOXB4 protein. Nature medicine. 2003 Nov; 9(11): 1428-1432.

31. Liedtke S, Enczmann J, Waclawczyk S, Wernet P, Kogler G. Oct4 and its pseudogenes confuse stem cell research. Cell stem cell. 2007 Oct 11; 1(4):364-366. [PubMed: 18371374]

32. Chaurasia P, Gajzer DC, Schaniel C, D'Souza S, Hoffman R. Epigenetic reprogramming induces the expansion of cord blood stem cells. The Journal of clinical investigation. 2014 Jun 2; 124(6): 2378-2395. [PubMed: 24762436] 
a
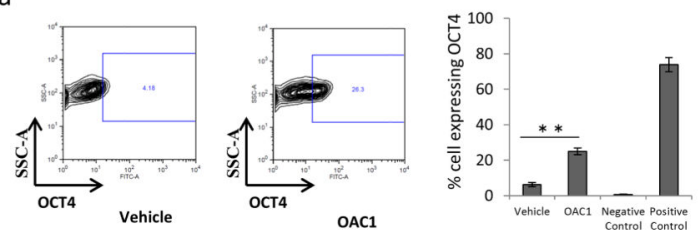

b

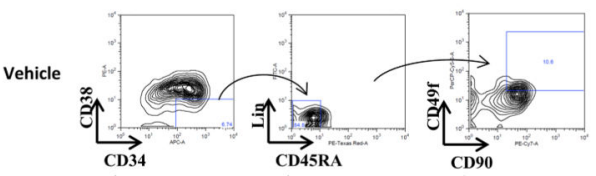

OAC1

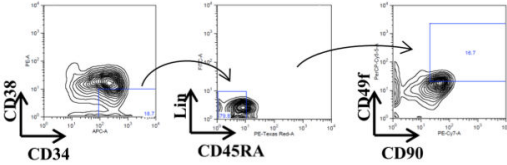

C

d
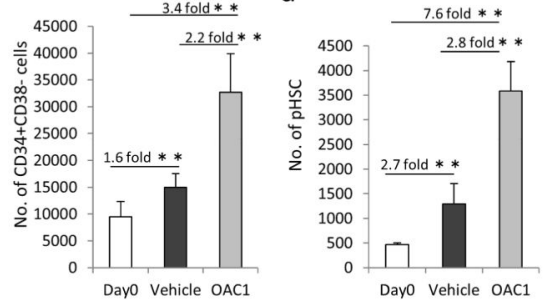

e

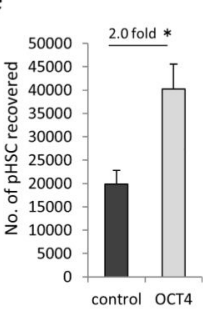

Figure 1.

Culture of human $\mathrm{CB} \mathrm{CD}_{3} 4^{+}$cells with OAC1 resulted in expansion of phenotypic HSC. (a) Expression of OCT4 in cultured $\mathrm{CB}$ CD $34^{+}$cells in the presence of vehicle control or OAC1. Left are the representative plots of OCT4 expression in vehicle control and OAC1 treated cells. Right is the quantification of the percentage of cells showing OCT4 expression. Negative control indicates OCT4 expression in MRC-5 fibroblast cells, positive control indicates OCT4 expression in $\mathrm{H} 9$ embryonic stem cells. $\mathrm{n}=4$, ** indicates $\mathrm{p}<0.01$. (b) Representative contour plots of Day 4 expansion of $\mathrm{CB} \mathrm{CD} 34^{+}$cells with $\mathrm{OAC} 1$ or vehicle control. (c) The number of $\mathrm{CD} 34^{+} \mathrm{CD} 38^{-}$cells significantly increased in OAC1-treated group compared to vehicle-treated group at Day 4. $\mathrm{n}=7$, ** indicates $\mathrm{p}<0.01$. (d) The number of $\mathrm{Lin}^{-} \mathrm{CD} 34^{+} \mathrm{CD} 38^{-} \mathrm{CD} 45 \mathrm{RA}^{-} \mathrm{CD} 90^{+} \mathrm{CD}^{-} 9 \mathrm{f}^{+}$cells significantly increased in OAC1-treated group compared to vehicle-treated group at Day 4. $n=7$, ** indicates $\mathrm{p}<0.01$. (e) CB CD34 ${ }^{+}$ cells were transduced with lentiviral vector pCSC-GW and pCSC-OCT4 as described in Materials and Methods section, the number of $\mathrm{HSC}\left(\mathrm{CD} 34^{+} \mathrm{CD} 38^{-} \mathrm{CD} 45 \mathrm{RA}^{-} \mathrm{CD} 90^{+} \mathrm{CD} 49 \mathrm{f}^{+}\right.$ cells) $/ 10^{6}$ total cells were calculated by using flow cytometry. $n=3, *$ indicates $\mathrm{p}<0.05$. Data represent the mean \pm s.d. 
a
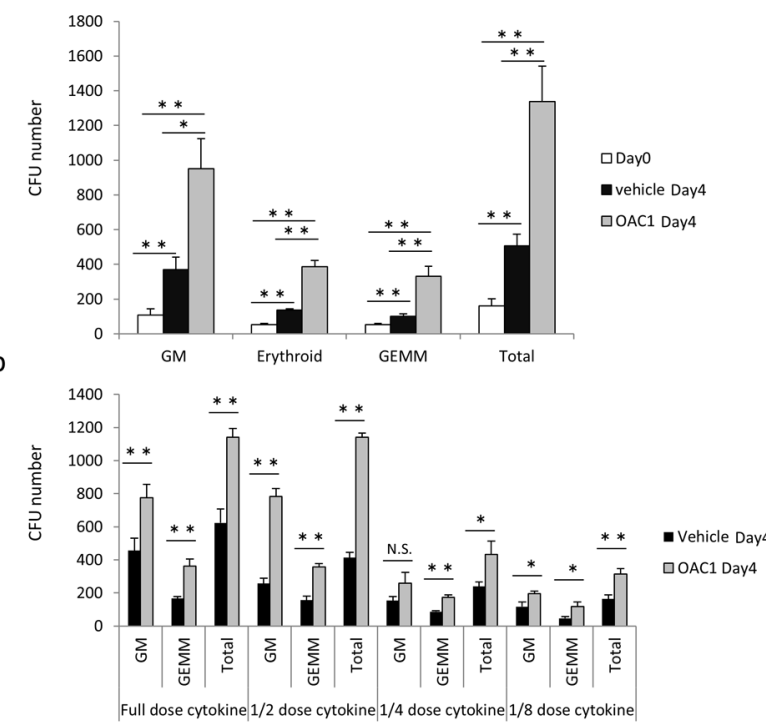

C

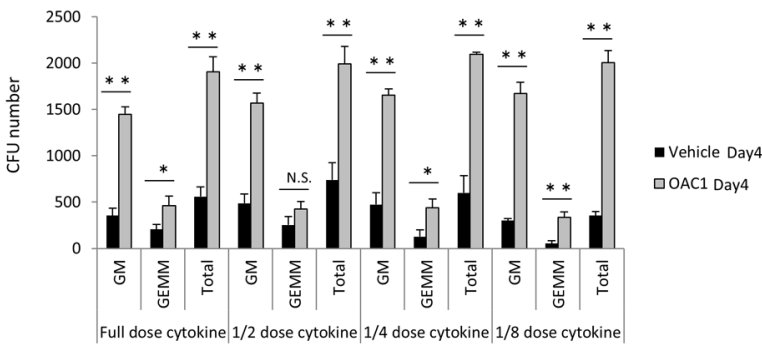

Figure 2.

Culture of $\mathrm{CB} \mathrm{CD} 34^{+}$cells with $\mathrm{OAC} 1$ resulted in increased number of CFUs. (a) $\mathrm{CFU}$ numbers in 1000 cells of Day 0 uncultured CD34+ ${ }^{+}$cells and the progeny of an equivalent number of $\mathrm{CD}_{3} 4^{+}$cells that were expanded in the presence of vehicle control or OAC1 for 4 days. $\mathrm{n}=3$, * indicates $\mathrm{p}<0.05$, ** indicates $\mathrm{p}<0.01$. (b) CFU numbers in the progeny of 1000 $\mathrm{CD}_{3}{ }^{+}$cells that were expanded in the presence of vehicle control or OAC1 for 4 days with different doses of cytokines. Full dose: 100ng/mL SCF, 100ng/mL TPO and 100ng/mL Flt3L; 1/2 dose: 50ng/mL SCF, 50ng/mL TPO and 50ng/mL Flt3L; $1 / 4$ dose: 25ng/mL SCF, 25ng/mL TPO and 25ng/mL Flt3L; $1 / 8$ dose: $12.5 \mathrm{ng} / \mathrm{mL}$ SCF, $12.5 \mathrm{ng} / \mathrm{mL}$ TPO and $12.5 \mathrm{ng} / \mathrm{mL}$ Flt $3 \mathrm{~L}$. $*$ indicates $\mathrm{p}<0.05, * *$ indicates $\mathrm{p}<0.01$, N.S. indicates $\mathrm{p}>0.05$. (c) CFU numbers in the progeny of $1000 \mathrm{CD}^{+} 4^{+}$cells that were expanded in the presence of vehicle control or OAC1 for 4 days and different doses of cytokines were only employed during CFU assay. Full dose: $1 \mathrm{U} / \mathrm{mL}$ erythropoietin, $50 \mathrm{ng} / \mathrm{mL}$ SCF, $10 \mathrm{ng} / \mathrm{mL}$ IL-3, and $10 \mathrm{ng} / \mathrm{mL}$ GM-CSF; $1 / 2$ dose: $0.5 \mathrm{U} / \mathrm{mL}$ erythropoietin, $25 \mathrm{ng} / \mathrm{mL} \mathrm{SCF}, 5 \mathrm{ng} / \mathrm{mL}$ IL-3, and $5 \mathrm{ng} / \mathrm{mL}$ GM-CSF; $1 / 4$ dose: $0.25 \mathrm{U} / \mathrm{mL}$ erythropoietin, $12.5 \mathrm{ng} / \mathrm{mL}$ SCF, $2.5 \mathrm{ng} / \mathrm{mL}$ IL-3, and 2.5 ng/mL GM-CSF; $1 / 8$ dose: $0.125 \mathrm{U} / \mathrm{mL}$ erythropoietin, $6.25 \mathrm{ng} / \mathrm{mL}$ SCF, $1.25 \mathrm{ng} / \mathrm{mL}$ IL-3, and $1.25 \mathrm{ng} / \mathrm{mL}$ GM-CSF. * indicates $\mathrm{p}<0.05$, ** indicates $\mathrm{p}<0.01$, N.S. indicates $\mathrm{p}>0.05$. Data represent the mean \pm s.d. 
a

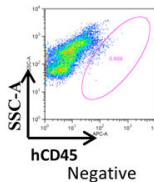

$b$
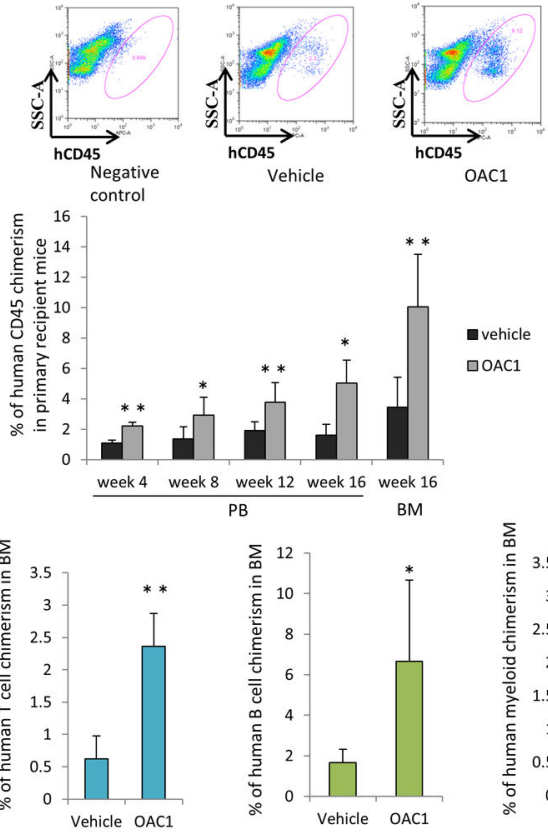

OAC
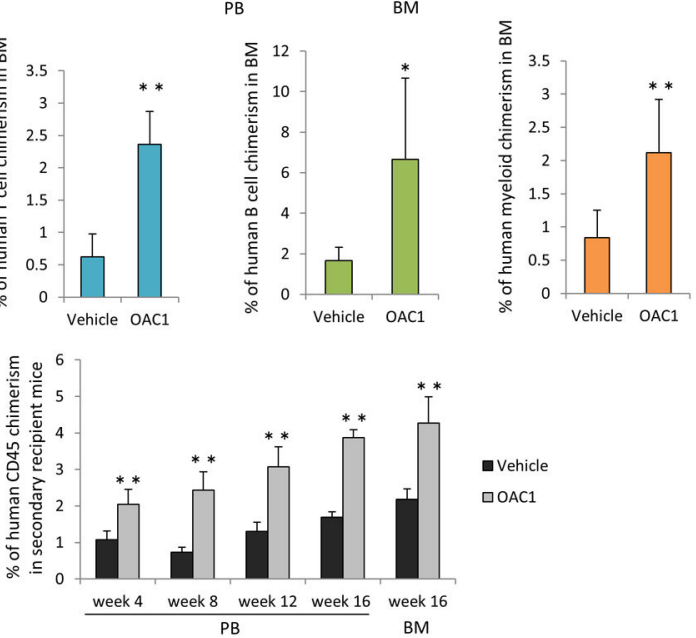

Figure 3.

Effect of OAC1 treatment on human $\mathrm{CB}$ CD34+ engraftment of NSG mice. NSG mice were transplanted with progeny of $50000 \mathrm{OAC} 1$ or vehicle control treated cells after sublethally irradiation. (a) Representative flow cytometric analysis of human engraftment in the bone marrow (BM) of NSG mice, 16 weeks after transplant. Left is from a mouse without transplantation (negative control), center and right are from mice transplanted with human $\mathrm{CB} \mathrm{CD} 34^{+}$cells cultured with vehicle control or OAC1 for 4 days. Human engraftment was assessed as the percentage of human $\mathrm{CD}^{4} 5^{+}$cells. (b) Peripheral blood (PB) was collected at different time points after transplantation and cells were stained for human CD45 percentage. Data are pooled from two independent experiments ( $\mathrm{n}=6-8$ mice for each group). $*$ indicates $\mathrm{p}<0.05$, ** indicates $\mathrm{p}<0.01$. (c) $\mathrm{T}$ cell $\left(\mathrm{CD} 3^{+}\right)$, B cell $\left(\mathrm{CD} 19^{+}\right)$and myeloid cell $\left(\mathrm{CD} 33^{+}\right)$chimerism in primary NSG mice bone marrow. Data are pooled from two independent experiments ( $\mathrm{n}=6-8$ mice for each group). $*$ indicates $\mathrm{p}<0.05$, ** indicates $\mathrm{p}<0.01$. (d) Human CD45 cell chimerism in the PB and BM from secondary recipient NSG mice $(\mathrm{n}=5$ mice for each group). $* *$ indicates $\mathrm{p}<0.01$. Data represent the mean \pm s.d. 
a

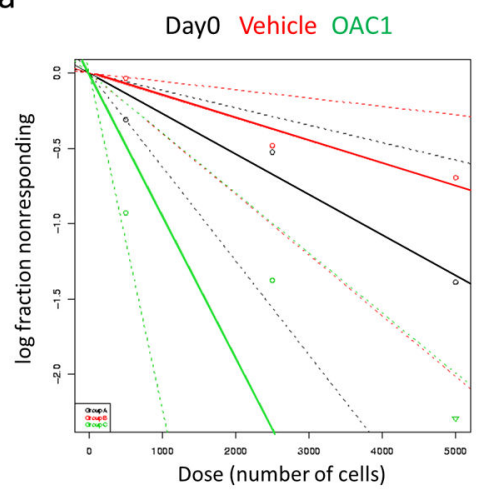

b

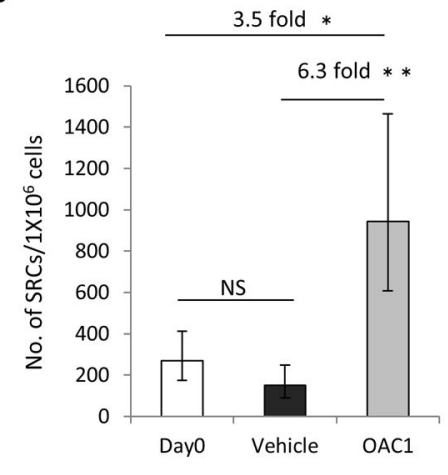

Figure 4.

The frequency of human SRCs in uncultured $\mathrm{CD}^{+} 4^{+}$cells and the progeny of the equivalent number of cells treated with vehicle control or OAC1. (a) Poisson statistical analysis of data from Table 1. Shapes represent the percentage of negative mice for each dose of cells. Solid lines indicate the best-fit linear model for each data set. Dotted lines represent $95 \%$ confidence intervals. (b) The number of SRCs in $1 \times 10^{6} \mathrm{CD} 34^{+}$cells. * indicates $\mathrm{p}<0.05$, ** indicates $\mathrm{p}<0.01$. Data represent the mean \pm s.e. 

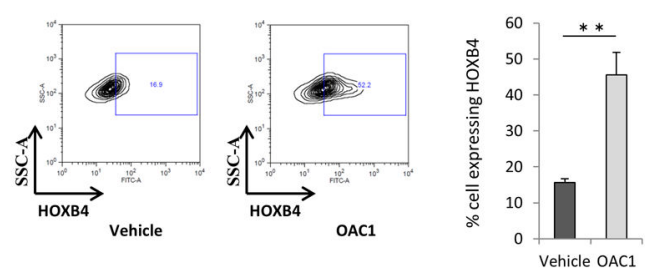

b

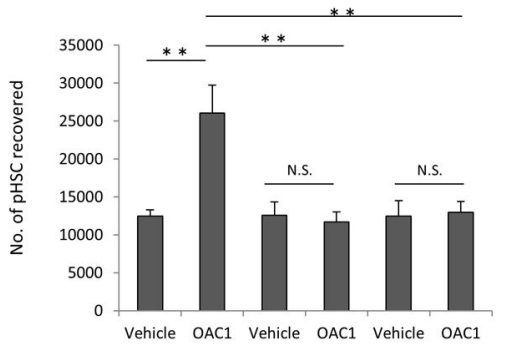

scrambled control

HOXB4 SIRNA

OCT4 SIRNA

C

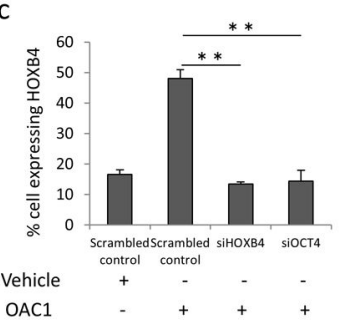

d

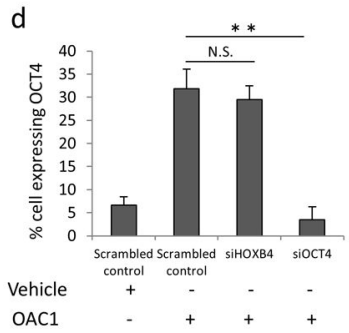

Figure 5.

HOXB4 mediates the effect of OAC1 on ex vivo expansion of HSC. (a) Expression of HOXB4 in the progeny of $\mathrm{CD} 34^{+}$cells after 4 days culture in the presence of vehicle control or OAC1. Left are the representative plots of HOXB4 expression in vehicle control and OAC1 treated cells. Right is the quantification of the percentage of cells showing HOXB4 expression. $\mathrm{n}=3$, ** indicates $\mathrm{p}<0.01$. (b) $\mathrm{CB} \mathrm{CD} 34^{+}$cells were transfected with $\mathrm{HOXB} 4$, OCT4 or scrambled (negative control) siRNA as described in Materials and Methods section, the number of $\mathrm{HSC}\left(\mathrm{Lin}^{-} \mathrm{CD} 34^{+} \mathrm{CD} 38^{-} \mathrm{CD} 45 \mathrm{RA}^{-} \mathrm{CD} 90^{+} \mathrm{CD} 49 \mathrm{f}^{+}\right.$cells $) / 10^{6}$ total cells were calculated by using flow cytometry. $\mathrm{n}=3$, N.S. indicates $\mathrm{p}>0.05$, ** indicates $\mathrm{p}<0.01$. (c) HOXB4 expression was analyzed by flow cytometry after transfection with HOXB4, OCT4 or scrambled siRNA and cultured for 4 days in the presence of vehicle control or OAC1. $\mathrm{n}=3$, ** indicates $\mathrm{p}<0.01$. (d) OCT4 expression was analyzed by flow cytometry after transfection with $H O X B 4, O C T 4$ or scrambled siRNA and cultured for 4 days in the presence of vehicle control or OAC1. $\mathrm{n}=3$, N.S. indicates $\mathrm{p}>0.05, * *$ indicates $\mathrm{p}<0.01$. Data represent the mean \pm s.d. 
Table 1

SRC frequency determined by limiting dilution assay in NSG mice

\begin{tabular}{|c|c|c|c|}
\hline Culture conditions & \multicolumn{2}{|c|}{ Cells transplanted } & $\begin{array}{c}\text { Number of mice with > 1\% human cell } \\
\text { chimerism/total number of mice }\end{array}$ \\
\hline \multirow{3}{*}{ Day 0 Uncultured } & & 500 & $1 / 4$ \\
\cline { 2 - 4 } & & 2500 & $2 / 5$ \\
\cline { 2 - 4 } & & 5000 & $3 / 4$ \\
\hline \multirow{4}{*}{ Vehicle control } & $\begin{array}{c}\text { Number of CD34+ cells at } \\
\text { starting }\end{array}$ & Number of cells transplanted & \\
\cline { 2 - 4 } & 500 & $3.5 \times 10^{3} \pm 0.8 \times 10^{2}$ & $0 / 5$ \\
\cline { 2 - 4 } & 2500 & $1.8 \times 10^{4} \pm 3.8 \times 10^{2}$ & $2 / 5$ \\
\cline { 2 - 4 } & 5000 & $3.5 \times 10^{4} \pm 7.5 \times 10^{2}$ & $2 / 4$ \\
\hline \multirow{3}{*}{ OAC1 } & 500 & $3.6 \times 10^{3} \pm 1.2 \times 10^{2}$ & $3 / 5$ \\
\cline { 2 - 4 } & 2500 & $1.8 \times 10^{4} \pm 6.0 \times 10^{2}$ & $3 / 4$ \\
\cline { 2 - 4 } & 5000 & $3.6 \times 10^{4} \pm 1.2 \times 10^{3}$ & $5 / 5$ \\
\hline
\end{tabular}




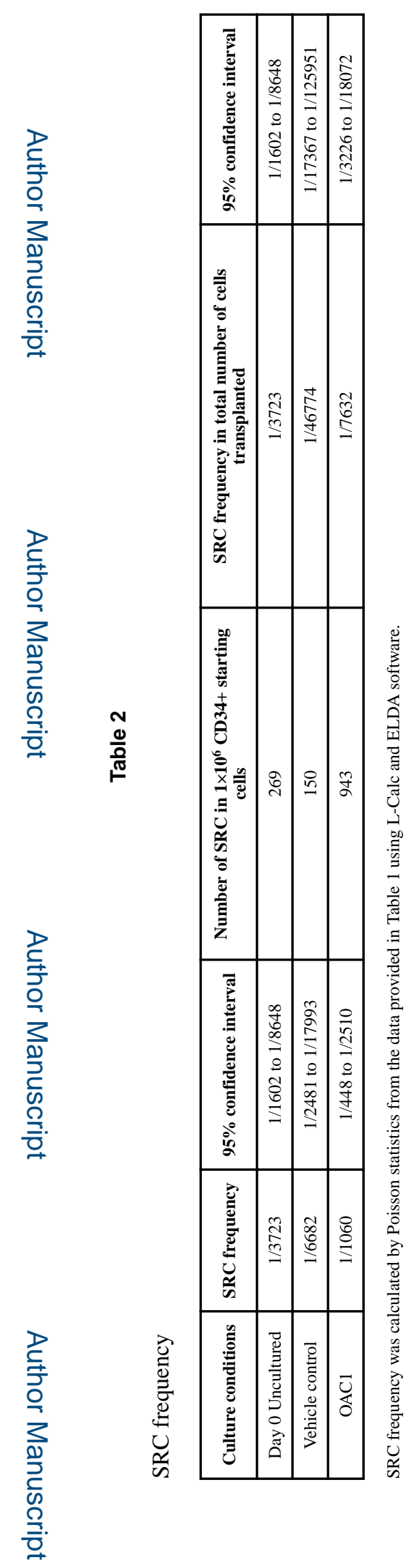

